\title{
Discriminate Scoring Skills and Non-Scoring Skills According to Results in the Brazilian Men's Volleyball SuperLeague
}

\author{
Aluizio Otávio Gouvêa Ferreira Oliveira ${ }^{1,2,3}$, Luís Miguel Teixeira Vaz ${ }^{1,5}$, Júlio Cesar \\ Pastore $^{1,4}$, Paulo Vicente João ${ }^{1,5}$
}

\begin{abstract}
Affiliations: 'University of Trás-os-Montes and Alto Douro (UTAD), Department of Sports Sciences, Vila Real, Portugal, 2Faculty of Communication Technology and Tourism Olinda (FACOTTUR), Department of Sports Sciences, Olinda, Brazil, ${ }^{3}$ University Mauricio de Nassau (UNINASSAU), Department of Sports Sciences, Caruaru, Brazil, ${ }^{4} U$ niversity Estácio de Sá (Unesa), Rio de Janeiro, Brazil, ${ }^{5}$ University of Trás-os-Montes and Alto Douro (UTAD), Research Center in Sport Sciences, Health and Human Development (CIDESD), Vila Real, Portugal
\end{abstract}

Correspondence: A. Oliveira, Faculty of Communication Technology and Tourism Olinda - FACOTTUR, Department of Sports Sciences, Av. Getúlio Vargas 1360, 53030-010 Olinda-PE, Brazil. E-mail: aluizio.gouvea@gmail.com

ABSTRACT This study analysed the Brazilian SuperLeague Men's Volleyball 2011/2012 season and 2012/2013 season, in an attempt to identify the game-related factors allowing the determination of winning and losing teams. All games $(n=294)$ of the Brazilian SuperLeague Men's Volleyball 2011/2012 season and 2012/2013 season were analysed. In the 2011/2012 season, the Total Set Actions (TSETA) and Total Points Made (TPM) were factors that determined the game result as a defeat. The factor that determined the victory was the Total Attack Actions (TAA). In the 2012/2013 season, the factors Total Serve Actions (TSA) and Total Set Actions (TSETA) generated victory, and the factors that led to defeat were the TPM and TAA. The scoring skill (TPM) determined the final game result but surprisingly is associated with the defeat and the TSA with victory. The scoring skill (TAA) determining the result of the game was probably associated with victory in the 2011/2012 season and defeat in the 2012/2013 season. The non-scoring skill TSETA determined the result of the game, and this may be associated with defeat in the 2011/2012 season and the victory in the 2012/2013 season.

KEY WORDS Match Analysis, Statistics Related-Gaming, Scoring Skill, Non-Scoring Skill and Volleyball

@MJSSMontenegro

DISCRIMINATE SCORING SKILLS AND NON-SCORING SKILLS

http://mjssm.me/?sekcija=article\&artid=155

\section{Introduction}

According to Ortega, Villarejo and Palao (2009), the analysis of game statistics, regarding individual and collective skills, is a tool that can be used to describe and monitor the behaviour of opponents. Although the limitations may arise from the different variables used in these studies (Hughes, Cooper, \& Nevill, 2002), this type of data is always useful for a greater knowledge of the game.

As Sampaio, Janeira, Ibanez and Lorenzo (2006) explain, the identification and codification of game action statistics, used as performance scorers, have been presented in the literature in order to contribute to the improvement of different sports.

The study of sport through the observation of players and the behaviour of teams is of vital importance for the organization, design, teaching and training of teams; most of these research studies analyse the different performance indicators within each sporting modality (Shaughnessy, 2006). Performance indicators are defined as the selection and combination of variables that define some aspect of performance and help in achieving athletic success (Hughes \& Bartllet, 2002). These indicators are an ideal pro-performance factor that must be present in the sports mode to achieve this performance and can be used to predict the future behaviour of the activity (Ortega et al., 2009). 
A performance indicator is a selection or combination of action variables that affect some or all aspects of a performance. Analysts and technicians use performance indicators to evaluate the performance of an individual, a team, or team elements (Lobietti, Coleman, Pizzichillo \& Merni, 2010; Marcelino, Mesquita, Sampaio \& Moraes, 2010). They are often used in a comparative way, with opponents, other athletes or groups of athletes or teams, but often they are used in isolation as a measure of the performance of a team or a single person (Hughes \& Bartlett, 2002).

A limitation was that some studies used a univariate technique in the data analysis, not enabling inferences about the interaction between the different performance indicators nor about the degree of importance of each of them on the final performance of the team.

In that sense, volleyball is an active game that provides a confrontational property between two teams. Its primary purpose is to shoot the ball in the team's court or to commit a fault or foul. With the change of the rules and the scoring system, the period of the game is reduced, generating ball possession disputes with maximum intensity and speed to overcome the opponent (Castro, Matias, Carvalho, Berriel \& Greco, 2013).

Thus, in order to favour the understanding of the structure of the game, as well as its training dynamics, the development of this is typically divided into two major phases: the side-out or complex 1 (K1) (Zetou \& Tsigilis, 2007; Castro \& Mesquita, 2008) as the attack carried out from the reception of the opponent's service, and the side-out transition or complex 2 (K2) (Zetou, Moustakidis, Tsigilis \& Komninakidou, 2006; Castro \& Mesquita, 2008), which refers to the attack carried out from the defence of the opposing attack (Lerbach \& Vianna, 2007).

Marcelino et al. (2010) report that the technical fundamentals of volleyball are actions that grant the player offensive action (Serve, Attack and Block), the structure of the attack (Reception and Set), and defensive action (Block and Defence). It is understood that the quality in the realization of the fundamentals of the team will affect the game, which can lead to victory or defeat.

Little is known about this subject in Brazilian volleyball. The aim of this paper is to understand the ideal combination of these indicators to help achieve success in the Brazilian Men's Volleyball SuperLeague. In this sense, the objective of the present study is to identify which statistics related to the game allow determining the result (victory and defeat), the actions of game "Scoring Skills" (Attack, Serve and Block) and the actions of game "Non-Scoring Skills" (Pass, Reception and Defence), in the Brazilian Men's Volleyball SuperLeague.

\section{Methods}

Sample

All games ( $n=294$ ) of the Men's Volleyball Brazilian SuperLeague of the 2011/2012 season $(n=148)$ and the $2012 / 2013$ season $(n=146)$ were analysed.

\section{Instruments and Variables}

The data were collected from official game scouts through the official website of the Brazilian Volleyball Confederation (CBV), provided by SCConsultoria, a private company dedicated to the performance measurement of the teams of the Brazilian SuperLeague Volleyball. In view of the difficulties inherent in carrying out this type of study, the use of secondary data with a high degree of reliability has been approved by those who use them in a careful way to conduct investigations in the field of sport.

The dependent variable was the Match Result (MR) - Victory or Defeat and the independent variables were Total of Points Made (TPM); Number of Substitutions (NS); Total Attack Points (TAP); Total Attack Actions (TAA); Total Block Points (TBP); Total Block Actions (TBA); Total Serve Points (TSP); Total Serve Actions (TSA); Adversary Errors (AE); Total Excellent Defence (TED); Total Defence Actions (TDA); Total Excellent Set (TES); Total Set Actions (TSETA); Total Excellent Reception (TER); Total Reception Actions (TRA).

\section{Reliability Analysis}

The reliability of the observations was tested in $10 \%$ of the sample ( 29 assisted games) by comparing the 14 variables in the results obtained from the Brazilian Volleyball Confederation database, showing interobserver Cohen $(\mathrm{K})$ inter-observer between 0.92 and 1 The data reliability analysis was performed with the Statistical Package for Social Sciences (SPSS) version 20.0 and with a significance level of $5 \%$.

\section{Statistical analysis}

Initially, the Kolmogorov-Smirnov test was used to analyse the normal distribution of the data. The value of the variables was less than 0.05 , thus not presenting a normal distribution. As non-parametric data and the samples are not paired, the Mann-Whitney Test was used to evaluate the differences between the general averages of all victories with the general averages of all defeats.

Finally, Discriminate Analysis (DA) was used to evaluate the significance of game statistics on whether the team is likely to be the winner or loser. The statistical significance of the obtained function was analysed, and through the Structural Canonical Coefficients (SCC), the most powerful indicators were identified. With this, it was considered that the SCC with statistical significance would have values equal to or greater than 0.30 , in other words SCC $\geq 0.30$ (Tabachnick \& Fidell, 2007). 
For all statistical treatment, Microsoft Excel Software version 2010 was used to catalogue and organize all the data and the Statistical Package for Social Sciences (SPSS) version 20.0 software to perform the descriptive, variance and discriminate analyses. The level of significance was respected $\mathrm{p}<0.05$, the confidence level was $95 \%$, and for $\mathrm{p}<0.01$ the confidence level was $99 \%$.

Results

Table 1 shows the values of the comparison of the data regarding victories and defeats for the 2011/2012 season.

TABLE 1 Comparison of the factors in the victories and defeats of the Brazilian SuperLeague of Men's Volleyball 2011/2012 using the Mann-Whitney Test

\begin{tabular}{lccccc} 
& $\begin{array}{c}\text { Victories } \\
(\mathbf{n = 1 4 8})\end{array}$ & $\begin{array}{c}\text { Defeats } \\
(\mathbf{n = 1 4 8})\end{array}$ & $\begin{array}{c}\text { Mann-Whitney } \\
\mathbf{U}\end{array}$ & $\begin{array}{c}\text { Wilcoxon } \\
\mathbf{W}\end{array}$ & Sig. \\
\hline Factors & (means $\pm \mathbf{s d})$ & (means $\pm \mathbf{s d})$ & $\mathbf{( U )}$ & $\mathbf{( Z )}$ & $(\boldsymbol{p})$ \\
\hline (TPM) & $91.33 \pm 15.03$ & $80.89 \pm 19.09$ & 7569.50 & 18595.50 & $0.00^{*}$ \\
(NS) & $7.25 \pm 2.98$ & $8.75 \pm 2.63$ & 7713.50 & 18739.50 & $0.00^{*}$ \\
(TAP) & $49.59 \pm 10.32$ & $45.45 \pm 11.65$ & 8800.00 & 19826.00 & $0.03^{*}$ \\
(TAA) & $95.12 \pm 22.75$ & $98.66 \pm 21.07$ & 9839.00 & 20865.00 & 0.13 \\
(TBP) & $9.93 \pm 3.62$ & $7.83 \pm 3.66$ & 7365.50 & 18391.50 & $0.00^{*}$ \\
(TBA) & $47.47 \pm 11.55$ & $44.67 \pm 12.93$ & 9271.00 & 20297.00 & $0.02^{*}$ \\
(TSP) & $4.53 \pm 2.27$ & $3.42 \pm 2.26$ & 7714.50 & 18740.50 & $0.00^{*}$ \\
(TSA) & $89.88 \pm 16.18$ & $81.86 \pm 18.57$ & 7924.00 & 18950.00 & $0.00^{*}$ \\
(AE) & $27.76 \pm 6.38$ & $24.09 \pm 6.75$ & 7563.00 & 18589.00 & $0.00^{*}$ \\
(TED) & $33.99 \pm 9.45$ & $30.72 \pm 9.92$ & 8930.00 & 19956.00 & $0.01^{*}$ \\
(TDA) & $62.46 \pm 15.48$ & $62.71 \pm 15.10$ & 10723.00 & 21749.00 & 0.76 \\
(TES) & $26.88 \pm 9.50$ & $25.09 \pm 9.77$ & 9621.00 & 20647.00 & 0.07 \\
(TSETA) & $91.70 \pm 21.74$ & $95.62 \pm 20.35$ & 9699.50 & 20725.50 & 0.09 \\
(TER) & $34.39 \pm 11.06$ & $36.97 \pm 12.23$ & 9543.50 & 20569.50 & 0.06 \\
(TRA) & $65.52 \pm 16.27$ & $74.94 \pm 13.11$ & 7325.00 & 18351.00 & $0.00^{*}$ \\
\hline
\end{tabular}

Note: * Level of Significance $(p<0.05)$; Total of Points Made (TPM); Number of Substitutions (NS); Total Attack Points (TAP); Total Attack Actions (TAA); Total Block Points (TBP); Total Block Actions (TBA); Total Serve Points (TSP); Total Serve Actions (TSA); Adversary Errors (AE); Total Excellent Defence (TED); Total Defence Actions (TDA); Total Excellent Set (TES); Total Set Actions (TSETA); Total Excellent Reception (TER); Total Reception Actions (TRA).

Significant differences were observed in almost all variables, with the exception of Total Attack Actions (TAA) $(p=0.13)$, Total Defence Actions (TDA) $(p=0.76)$, Total Excellent Set (TES) $(p=0.07)$, Total Set Actions (TSETA) $(\mathrm{p}=0.09)$ and Total Excellent Reception (TER) $(\mathrm{p}=0.06)$.

TABLE 2 CCE values of the Discriminating Function of the factors between victories and defeats of all the games of the Brazilian SuperLeague of Men's Volleyball 2011/2012

\begin{tabular}{|c|c|}
\hline \multirow[t]{2}{*}{ Factors } & \multirow{2}{*}{$\begin{array}{c}\text { Function } \\
1 \\
|S C|\end{array}$} \\
\hline & \\
\hline Total Attack Actions (TAA) & $-0.81^{*}$ \\
\hline Total Set Actions (TSETA) & $0.70^{*}$ \\
\hline Total Points Made (TPM) & $0.42^{*}$ \\
\hline Total Attack points (TAP) & -0.24 \\
\hline Total Serve Actions (TSA) & -0.18 \\
\hline Adversary Errors (AE) & -0.10 \\
\hline Total Excellent Reception (TER) & 0.09 \\
\hline Total Serve Points (TSP) & 0.06 \\
\hline Number of Substitutions (NS) & 0.05 \\
\hline Total Excellent Set (TES) & 0.05 \\
\hline Total Reception Actions (TRA) & 0.05 \\
\hline Total Defence Actions (TDA) & 0.05 \\
\hline Total Block Actions (TBA) & 0.04 \\
\hline Total Excellent Defence (TED) & 0.02 \\
\hline Total Block Points (TBP) & -0.01 \\
\hline Wilks' Lambda & 0.12 \\
\hline Qui-Square & 614.18 \\
\hline Auto-Value & 7.60 \\
\hline Canonical Correlation & 0.94 \\
\hline Central Mean - Defeats & 2.75 \\
\hline Central Mean - Victories & -2.75 \\
\hline
\end{tabular}

Note: * $|\mathrm{SC}| \geq 0.30$ 
In Table 2, the results of the discriminate analysis between victories and defeats for the factors of all games are shown in the general form of the 2011/2012 season.

The values of CCE of the factors TSETA $(C C E=0.70)$ and TPM $(C C E=0.42)$ were discriminated so that the Match Result (MR) was negative, in this case, the defeat. The factor that determined that the MR was positive, that is, the victory, was the TAA $(\mathrm{CCE}=-0.81)$.

TABLE 3 Comparison of the factors in the victories and defeats of the Brazilian SuperLeague of Men's Volleyball 2012/2013 using the Mann-Whitney Test

\begin{tabular}{|c|c|c|c|c|c|}
\hline & $\begin{array}{l}\text { Victories } \\
(n=146)\end{array}$ & $\begin{array}{l}\text { Defeats } \\
(n=146)\end{array}$ & $\begin{array}{c}\text { Mann-Whitney } \\
\text { U }\end{array}$ & $\begin{array}{c}\text { Wilcoxon } \\
\text { W }\end{array}$ & Sig. \\
\hline Factors & $(m \pm s d)$ & $(m \pm s d)$ & (U) & $(Z)$ & $(p)$ \\
\hline (TPM) & $93.26 \pm 14.43$ & $82.95 \pm 19.61$ & 7548.50 & 18279.50 & $0.00^{*}$ \\
\hline (NS) & $7.05 \pm 3.20$ & $8.96 \pm 2.66$ & 6792.00 & 17523.00 & $0.00^{*}$ \\
\hline (TAP) & $51.58 \pm 10.03$ & $46.69 \pm 12.26$ & 8250.50 & 18981.50 & $0.00^{*}$ \\
\hline$(\mathrm{TAA})$ & $101.01 \pm 25.99$ & $104.22 \pm 23.88$ & 9920.50 & 20651.50 & 0.31 \\
\hline (TBP) & $10.81 \pm 3.45$ & $8.51 \pm 4.37$ & 6700.00 & 17431.00 & $0.00^{*}$ \\
\hline$(\mathrm{TBA})$ & $51.21 \pm 13.34$ & $47.73 \pm 14.07$ & 9067.00 & 19798.00 & $0.03^{*}$ \\
\hline (TSP) & $4.26 \pm 2.05$ & $3.04 \pm 1.98$ & 6902.50 & 17633.50 & $0.00^{*}$ \\
\hline (TSA) & $91.77 \pm 14.93$ & $83.75 \pm 19.01$ & 8012.00 & 18743.00 & $0.00^{*}$ \\
\hline$(\mathrm{AE})$ & $26.64 \pm 5.72$ & $24.77 \pm 6.43$ & 8676.00 & 19407.00 & $0.01 *$ \\
\hline (TED) & $37.29 \pm 10.73$ & $33.73 \pm 11.61$ & 8850.50 & 19581.50 & $0.01 *$ \\
\hline (TDA) & $65.37 \pm 16.96$ & $66.47 \pm 16.69$ & 10246.00 & 20977.00 & 0.57 \\
\hline (TES) & $27.86 \pm 9.78$ & $24.54 \pm 11.47$ & 8342.00 & 19073.00 & $0.00^{*}$ \\
\hline (TSETA) & $98.90 \pm 24.50$ & $101.43 \pm 22.87$ & 9967.50 & 20698.50 & 0.34 \\
\hline (TER) & $34.38 \pm 12.42$ & $35.88 \pm 13.49$ & 9957.50 & 20688.50 & 0.33 \\
\hline (TRA) & $68.92 \pm 17.56$ & $77.04 \pm 13.79$ & 7796.00 & 18527.00 & $0.00^{*}$ \\
\hline
\end{tabular}

Note: * Level of Significance $(p<0.05)$

In the classification of Matrix of Confusion, the Discriminate Function between victories and losses for the factors of all games in the general form of the 2011/2012 season, the success of the adjustment quality of the DA was of $100 \%$ in both game results. In defeats, 100\% of the games (148 of 148) are classified successfully. The same is also true of victories: 148 games of 148 are classified successfully.

TABLE 4 CCE values of the Discriminating Function of the factors between victories and defeats of all games of the Brazilian SuperLeague of Men's Volleyball 2012/2013

\begin{tabular}{|c|c|}
\hline \multirow[t]{2}{*}{ Factors } & $\begin{array}{c}\text { Function } \\
1 \\
\end{array}$ \\
\hline & $|\mathbf{S C}|$ \\
\hline Total Points Made (TPM) & $1.78^{*}$ \\
\hline Total Serve Actions (TSA) & $-1.72^{*}$ \\
\hline Total Set Actions (TSETA) & $-0.81^{*}$ \\
\hline Total Attack Actions (TAA) & $0.53^{*}$ \\
\hline Total Block Points (TBP) & 0.23 \\
\hline Total Attack Points (TAP) & 0.22 \\
\hline Total Block Actions (TBA) & -0.17 \\
\hline Total Reception Actions (TRA) & -0.15 \\
\hline Number of Substitutions (NS) & 0.15 \\
\hline Total Defence Actions (TDA) & 0.13 \\
\hline Total Excellent Set (TES) & -0.06 \\
\hline Total Excellent Reception (TER) & 0.04 \\
\hline Total Serve Points (TSP) & 0.03 \\
\hline Total Excellent Defence (TED) & 0.01 \\
\hline Adversary Errors $(\mathrm{AE})^{* *}$ & -0.06 \\
\hline Wilks' Lambda & 0.14 \\
\hline Qui-Square & 560.28 \\
\hline Auto-Value & 6.29 \\
\hline Canonical Correlation & 0.93 \\
\hline Central Mean - Defeats & 2.50 \\
\hline Central Mean - Victories & -2.50 \\
\hline
\end{tabular}

Note: ${ }^{*}|\mathrm{SC}| \geq 0.30 ;{ }^{* *}$ Unused variable in the analysis, because as failed tolerance test 
Table 3 shows the comparison values of the victories and defeats data for the 2012/2013 season.

Significant differences were observed in almost all variables, with the exception of Total Attack Actions (TAA) $(\mathrm{p}=0.31)$, Total Defence Actions (TDA) $(\mathrm{p}=0.57)$, Total Set Actions (TSETA) $(\mathrm{P}=0.34)$ and Total Excellent Reception (TER) $(\mathrm{p}=0.33)$.

Table 4 shows the results of the discriminate analysis between victories and defeats for the factors of all games in the general form of the 2012/2013 season.

The values of CCE of the factors TSA $(\mathrm{CCE}=-1.72)$ and TSETA $(\mathrm{CCE}=-0.81)$ generated the positive MR, in this case possibly associated with victory. However, the factors that caused the MR to be negative (i.e. possibly associated with defeat) were $(\mathrm{TPM})=1.78$ and $(\mathrm{TAA}) \mathrm{CCE}=0.53$.

In the classification of the confusion matrix of the Discriminating Function between victories and defeats for the factors of all games in the general form of the 2012/2013 season, the success of DA adjustment quality was $100 \%$ in both game results. In defeats, $100 \%$ of the games (146 of 146) are classified successfully. The same is also true of victories: 146 games of 146 are classified successfully.

\section{Discussion}

In the 2011/2012 season, as was shown in Table 1, significant differences were observed in which the winning teams obtained higher averages of Total Points Made (TPM), Total Attack Points (TAP), Total Block Points (TBP), Total Block Actions (TBA), Total Serve Points (TSP), Total Serve Actions (TSA), Adversary Errors (AE) and Total Excellent Defence (TED) than the losing teams did, thus achieving victory.

Some researchers believe that teams that are at a disadvantage in the game may take more risks when serving, probably because they have nothing to lose (João, Leite, Mesquita \& Sampaio, 2010). However, as Yiannis, Panagiotis, Ioannis and Alkinoi (2004), when they risk more, these teams also end up failing more frequently, thus increasing the number of errors. In contrast, if they take chances, the opposing reception will be more complicated, increasing the prospects for error of the part of the other team.

The literature on the volleyball block points to its importance to the game result (Afonso, Mesquita, Marcelino \& Silva, 2010; Palao, Santos \& Ureña, 2004). Organization through strategies and trainings of triple block can increase the possibility of successful blocking. Palao (2008) determined that successful blocking offers more chances to win. In addition, blocking is the first terminal action (Scoring Skill) that can lead to an opponent's attack and can result in a direct point.

In relation to the attack points, game analysis studies (Costa, Ferreira, Junqueira, Afonso \& Mesquita, 2011; Costa, Mesquita, Greco, Ferreira \& Moraes, 2011; Garcia-Hermoso, Dàvila-Romero \& Saavedra, 2013; Marcelino, Mesquita \& Sampaio, 2011) in this study, we found that the point in volleyball is derived mainly from the attack and is directly related to the success of the game (Garcia-Hermoso et al. 2013; Marcelino et al., 2011).

Instead, losing teams achieved the highest averages of Number of Substitutions (NS) and Total Reception Actions (TRA) that the winning teams did, even though they did not achieve victory. It is not enough to just carry out more reception actions, but to execute them with excellence; not to obtain error in the reception is a factor that distinguishes the performance of the teams (Silva, Lacerda \& João, 2014, García-Alcaraz, Palao \& Ortega, 2014).

The discriminatory factor shown in Table 2, which caused the MR to be positive, was the TAA (CCE $=-0.81$ ). Surprisingly it is unlike the perceived averages, since the losing teams presented a higher average of TAA compared to the winning teams. However, it should be noted that this difference in means was not significant. Thus, it is assumed that the winning teams were able to take advantage of the attack actions and convert them into more attack points, which is evidenced by the significant difference in the averages of TAP.

The discriminatory factors that caused the (MR) to be negative were the (TSETA) CCE $=0.70$ and (TPM) $\mathrm{CCE}=0.42$ because the score was close to a mean of 2.75 , which caused the team's defeat. In fact, the average of (TSETA) $(m=95.62)$ of the defeated teams was higher than that of the winning teams $(m=91.70)$, although it was not a significant difference. Even if a team performs more setting actions, it is not a condition that it has a positive MR, because, in order to be a good condition in the setting action, the team must first have a good reception and then increase the probability of obtaining the point of attack and, consequently, victory (Matias \& Greco, 2011).

In the 2012/2013 season of the Brazilian Men's Volleyball SuperLeague, significant differences were found in Table 3: the winning teams obtained the highest averages of Total Points Made (TPM), Total Attack Points (TAP), Total Block Points (TBP), Total Block Actions (TBA), Total Serve Points (TSP), Total Serve Actions (TSA), Adversary Errors (AE) and Total Excellent Defence (TED) than the losing teams did; thus, the only difference between the seasons was that in 2011/2012 the average of the Total Excellent Set (TES) of the winning teams was also higher than that of the losing teams, but with a significant difference.

In contrast, losing teams have achieved the highest averages of Number of Substitutions (NS) and Total Reception Actions (TRA) than the winning teams did, even though they did not reach victory, just like in 
the 2011/2012 season. A team performing more reception actions is likely to lead to more errors in the same actions. Several studies have found an association between reception effectiveness and effects on the result of the match (Silva et al., 2014).

Regarding the discriminatory values, as seen in Table 4 , the results of CCE of the factors TAA (CCE $=0.53$ ) and TPM $(\mathrm{CCE}=1.79)$ were discriminate that the $(\mathrm{MR})$ was negative, due to the score being close to a central mean of 2.50 that influence the team in the case, to the defeat. In fact, the average of (TAA) $(\mathrm{m}=104.22)$ of the defeated teams was higher than that of the winning teams $(\mathrm{m}=101.01)$, although it was not a significant difference. Even though a team can perform more attack actions, more attack errors can occur, so the attack error provides the direct point to the opponent, increasing the chances of defeat (Costa, Barbosa, Freire, Matias \& Greco, 2014; Garcia-Hermoso et al., 2013). Regarding the attack, Cerrato, Palao, Marzo, Puche \& Ureña (2007) verified that the speed of the shot varies between men $(61.2 \mathrm{Km} / \mathrm{h}$ and $112.3 \mathrm{~km} / \mathrm{h})$ and has been increasing in recent years.

The factors that defined the MR as positive were the (TSA) CCE $=-1.72$ and (TSETA) CCE $=-0.81$. because the score was close to a mean of -2.50 that influenced the team: in this case, to victory. These discriminatory values are further substantiated by the highest average (TAS) $(m=91.77)$ of the winning teams compared to the losing teams $(\mathrm{m}=83.75)$. In volleyball, the serve has become an influential action of attack and, at the same time, of defence: from attack, when the direct point is obtained, and defence, making reception difficult and preventing the opposing team from organizing a perfect attack (Mackenzie, Kortegaard, LeVangie \& Barro, 2012).

The average $($ TSETA $)(\mathrm{m}=98.90)$ of the winning teams, although smaller than that of the losing teams $(\mathrm{m}=$ 101.43), however was not a significant difference, was a discriminate factor to the (MR) positive, due to the better use of execution action (TES) $(\mathrm{m}=24.54)$ of the losing teams compared to the (TES) average $(\mathrm{m}=27.86)$ of the winning teams, with a significant difference. The quality of the reception or the defence influences when it is desirable to prepare offensive situations appropriate to the attacker (Claver Rabaz, Jiménez Castuera, Gil Arias, Moreno Domínguez \& Moreno Arroyo, 2013). Even in cases in which the first touch feature is of poor quality, the excellent setting action tends to prepare offensive situations favourable to the attacker, as this may prevent the blocking from anticipating their tactical choice (Inkinen, Häyrinen \& Linnamo, 2013; Marcelino et al., 2010; Zetou et al., 2006).

\section{Conclusion}

According to the results obtained from this study, we can affirm that in the Brazilian Men's Volleyball SuperLeague 2011/2012 season, the factors that possibly caused the defeat were Total Set Actions (TSETA) and Total Points Made (TPM). The Total Attack Action (TAA) factor was probably key to the victory. In the Brazilian Men's Volleyball SuperLeague 2012/2013 season, the Total Serve Actions (TSA) and Total Set Actions (TSETA) factors were likely to have caused the victory. The factors that probably led to the defeat were Total Attack Actions (TAA) and Total Points Made (TPM).

Thus, in response to the objectives that we proposed, the Scoring Skill (TPM) determines the final game result, but it surprisingly is associated with defeat. The Scoring Skill (TSA) discriminates against the final game result, supposedly associated with victory. The Scoring Skill (TAA), however, determines the final game result, probably associated with both victory and defeat. In this case, it is related to the victory in the Brazilian Men's Volleyball SuperLeague 2011/2012 season and to the defeat in the Brazilian Men's Volleyball SuperLeague 2012/2013 season.

The Non-Scoring Skill (TSETA) determines the final game result, possibly being associated with both victory and defeat. In this situation, it is related to defeat in the Brazilian Men's Volleyball SuperLeague 2011/2012 season and to victory in the Brazilian Men's Volleyball SuperLeague 2012/2013 season.

We suggest that these variables should be considered as useful information for progress in the development of successful training procedures.

\section{REFERENCES}

Afonso J., Mesquita I., Marcelino R. and Silva J. (2010). Analysis of the setter's tactical action in highperformance women's volleyball. Kinesiology, 421, 82-89.

Castro, H. O., Matias, C. J. A., Carvalho, D. R., Berriel, G. P. and Greco, P. J. (2013). Eficácia do saque nas categorias de base do voleibol de Minas Gerais. Coleção Pesquisa em Educação Física, 12(1), 89-96.

Castro, J. and Mesquita, I. (2008). Implications of offensive spacing in elite male volleyball attack characteristics. Portuguese Journal of Sport and Sciences, 8(1), 114-25.

Cerrato, D., Palao, J., Marzo, P., Puche, P. and Ureña, A. (2007). Validez y Fiabilidade del radar para el control de la velocidad del remate en voleibol. Revista de Ciências de la Actividad y del deporte de la Universidade Católica San António, 2(6), 131-138.

Claver Rabaz, F., Jiménez Castuera, R., Gil Arias, A., Moreno Domínguez, A. and Moreno Arroyo, M. (2013). Relationship between performance in game actions and the match result. A study in volleyball training stages. Journal of Human Sport and Exercise - University of Alicante, 8(3Proc), 651-659. 
Costa, G.C., Barbosa, R.V., Freire, A.B., Matias, C.J.A.S. and Greco, P.J. (2014). Analysis of the structures of side-out with the outcome set in women's volleyball. Motricidade, 10(3), 40-49.

Costa, G., Ferreira, N., Junqueira, G., Afonso, J. and Mesquita, I. (2011). Determinants of attack tactics in youth male elite volleyball. International Journal of Performance Analysis in Sport, 11(1), 96-104.

Costa, G. C., Mesquita, I., Greco, P.J., Ferreira, N. N. and Moraes, J.C. (2011). Relationship serve, reception and attack the male youth volleyball. Journal Motriz, 17(1), 11-18.

García-Alcaraz, A., Palao, J. M. and Ortega, E. (2014). Technical-tactical performance profile of reception according to competition category in men volleyball. Kronos, 13(1).

Garcia-Hermoso, A., Dàvila-Romero, C. and Saavedra, J.M. (2013). Discriminatory power of game-related statistics in 14-15 year age group male volleyball, according to set. Perceptual and Motor Skills, 116(1), 132-143.

Hughes, M.D. and Bartlett, R.M. (2002). The use of performance indicators in performance analysis. Journal of sports sciences, 20(10), 739-754.

Hughes, M.D., Cooper, S. and Nevill, A. (2002). Analysis procedures for non-parametric data from performance analysis. International Journal of Performance Analysis in Sport, 2, 6-20.

Inkinen, V., Häyrinen, M. and Linnamo, V. (2013). Technical and tactical analysis of women's volleyball. Biomedical Human Kinetics, 5, 43-50.

João, P.V., Leite, N., Mesquita, I. and Sampaio, J. (2010). Sex differences in discriminative power of volleyball game-related statistics. Perceptual and Motor Skills, 11(3), 893-900.

Lerbach, A. M. and Vianna, N. (2007). Course for volleyball's coaches. National Coaches Course Level III. Rio de Janeiro: Brazilian Volleyball Confederation.

Lobietti, R., Coleman, S., Pizzichillo, E. and Merni, F. (2010). Landing techniques in volleyball. Journal of Sports Sciences, 28(13), 1469-1476.

Mackenzie, S., Kortegaard, K., LeVangie, M. and Barro, B. (2012). Evaluation of two methods of the jump float serve in volleyball. Journal of Applied Biomechanics, 28, 579-586.

Marcelino, R., Mesquita, I. and Sampaio, J. (2011). Effects of quality of opposition and match status on technical and tactical performances in elite volleyball. Journal of Sports Sciences, 29(7), 733-741.

Marcelino, R., Mesquita, I., Sampaio, J. and Moraes, J. C. (2010). Study of performance indicators in volleyball depending on the outcome of the set. Brazilian Journal of Physical Education and Sport, 24(1), 69-78.

Matias, C. J. and Greco, P. J. (2011). Analysis of offensive organization of the Volleyball Superleague setters. Brazilian Journal of Sports Science, 33(4), 1007-1028.

Ortega, E., Villarejo, D. and Palao, J.M. (2009). Differences in game statistics between winning and losing rugby teams in the Six Nations Tournament. Journal of Sports Science and Medicine, 8, 523-527.

Palao J. (2008). Options for analysis of the volleyball score sheet. International Journal of Performance Analysis in Sport, 8(2), 26-43.

Palao, J.M., Santos, J.A. and Ureña, A. (2004). Effect of team level on skill performance in volleyball. International Journal of Performance Analysis in Sport, 4(2), 50-60.

Sampaio, J., Janeira, M., Ibanez, S. and Lorenzo, A. (2006). Discriminant analysis of game-related statistics between basketball guards, forwards and centres in three professional leagues. European Journal of Sport Science, 6(3), 173-178.

Shaughnessy, D. M. O. (2006). Possession versus Position: Strategic Evaluation in AFL. Journal of Sports Science and Medicine, 5(4), 533-540.

Silva, M., Lacerda, D. and João, P. V. (2014). Game-related volleyball skills that influence victory. Journal of Human Kinetics, 41, 173-179.

Tabachnick, B. and Fidell, L. (2007). Using Multivariate Statistics. $5^{a}$ Ed. New York: Pearson Education, Inc.

Yiannis L., Panagiotis K., Ioannis A. and Alkinoi K. (2004). A comparative study of the effectiveness of the Greek national men's volleyball team with internationally top-ranked teams. International Journal of Volleyball Research, 4-9.

Zetou, E. and Tsigilis, N. (2007). Does effectiveness of skill in complex i predict win in men's Olympic volleyball games? Journal of Quantitative Analysis in Sports, 3(4), 1559-1570.

Zetou, E., Moustakidis, A., Tsigilis, N. and Komninakidou, A. (2006). Playing characteristics of men's Olympic Volleyball teams in complex II. International Journal of Performance Analysis in Sport, 6(1), 172-177. 